\title{
Burnout and Sense of Coherence in Dentistry Students of Karachi
}

\author{
Fasiha Moin Kazi ${ }^{1}$ \\ Shoaib Ahmed ${ }^{2}$ \\ Shama Asghar
}

\author{
BDS, MBA \\ MBBS, FCPS \\ BDS, FCPS
}

OBJECTIVE: This study aimed to assess burnout and sense of coherence levels in dentistry students of Karachi. METHODOLOGY: A cross-sectional study involving 361 students from four renowned dental colleges in Karachi was carried out. The students were distributed a questionnaire derived from the Mayo Clinic Well-being Index (WBI) and a modified 13-item Antonovsky's Sense of Coherence Scale (SOC scale). They were stratified on the basis of gender, age, professional year, institution, relationship status, history of chronic medical condition and history of chronic psychiatric condition. Scores for the WBI and SOC scale were calculated. For the WBI, a score of $>4$ was a sign that an individual was at risk of developing burnout or other severe outcomes. A high or low total score on the SOC scale demonstrated whether the individual was able to cope with his environment or not. MS Excel and SPSS version 23 were used for data compilation and statistical analysis. Descriptive statistics were calculated. Chi-square test of independence was applied to gauge any association between the strata and outcome variables. After determination of statistical difference, Mann Whitney-U Test and Kruskal Wallis Test were applied to compare the means where a significant association was found. A p-value of 0.05 or less was considered significant. RESULTS: The mean WBI score was found to be 4.07. Around 64\% respondents were at-risk of burnout (score > 4). A greater percentage of females was at risk (66\%) as compared to males (50\%). Third professional students were found to be the most affected (77\% with WBI score > 4 and 9\% in the low coherence category). The mean SOC score was found to be 36.39 (moderate levels of coherence). Overall, around 4-9\% of each professional year students exhibited a low sense of coherence. Age, relationship status, institution and a history of chronic medical and/or psychiatric condition were not found to have a significant association with the outcome variables ( $p>0.05)$.

CONCLUSION: A significant number of dentistry students are at risk of burn-out and suffer from a low sense of coherence. The risk factors need to be evaluated and solutions need to be found to create a healthy and conducive environment for the growth and learning of the students. More research needs to be focused on gathering data related to the well-being of dentistry students.

KEYWORDS: Burnout, sense of coherence, well-being index, dentistry.

HOW TO CITE: Kazi FM, Ahmed S, Asghar S. Burnout and sense of coherence in dentistry students of Karachi. J Pak Dent Assoc 2021;30(3):170-177.

DOI: https://doi.org/10.25301/JPDA.303.170

Received: 12 November 2020, Accepted: 28 March 2021

\section{INTRODUCTION}

$\mathrm{B}$ urnout was first defined in the 1970s by American psychologist Herbert Freudenberger as the "extinction of motivation or incentive, especially where one's own devotion to a cause or relationship fails to produce the desired results". ${ }^{1}$ It is known as the situation of physical or mental collapse caused by overwork or stress. Burnout consists of three dimensions; emotional exhaustion, depersonalization, and reduced personal accomplishment. Traditionally, burnout has been considered a workplace

1. Lecturer, Department of Science of Dental Materials, Dow Dental College, Karachi.

2. Executive Director, Department of Psychiatry, Institute of Behavioral Sciences, Dow University of Health Sciences, Karachi.

3. Associate Professor, Department of Bahria University Medical and Dental College, Karachi.

Corresponding author: "Dr. Fasiha Moin Kazi” < fas.kazi@ gmail.com > related concept but various studies have proven it to be very much prevalent amongst the medical student community ${ }^{2,3}$; dentistry being no exception. Infact there have been studies citing severe stress, emotional exhaustion and depression to be positively associated with the dental student and professional. ${ }^{3,4}$ The reason for this relationship may not be clearly defined; various factors have been implicated. For one, the very nature of the work may contribute to an overwhelming burden on the student The combination of intensive theoretical study and development of psychomotor skills, learning to deal with patients at an early stage during the course and a frequent encounter with intense pain related symptoms is a difficult domain for the average student. ${ }^{5}$ The associated difficulties related to workload, procurement and management of instruments, materials, meeting work quota, deadlines for assignments, attitudes of peers, patients, 
supervisors and the inevitable multiple examinations form the backdrop for a very stress intensive environment. ${ }^{5-7}$ In the local context where there is also the absence of adequate career counselling, many students opt for dentistry without actually knowing what to expect and many times with very preconceived unrealistic notions about the nature of the profession. Reality checks may occur after spending considerable time battling the issues in dentistry and may contribute to stress and uncertainty about the future. ${ }^{8}$ Considering the abundance of literature on the subject in the European context ${ }^{2,3,7,9}$, it remains to be seen whether this is a purely western phenomenon or not.

Internationally, the structure of dental programs varies to some degree from region to region. ${ }^{10}$ In some countries, a 5-6 year program is the norm whereas in others the traditional 4 year format is being followed. Integrated problem based teaching is being adopted by several modern universities whereas most centers follow the conventional teaching methodologies and find them as effective. Financial aids and programs are available to varying degrees as well. In Pakistan, bachelors in dental surgery comprises a 4 year program followed by a year of house job. ${ }^{11}$ The first two years are pre-clinical in nature consisting broadly of basic sciences in medicine and dentistry; lectures, tutorials and lab work which prepares the student for the upcoming clinical years. The clinical years consist of aggressive clinical course work along with rotations in various specialty outpatient departments of dentistry. The examination pattern has been varied lately with semester/modular pattern being followed in some institutions whereas annual examination pattern remained the norm in others. Lately, this has been revised to conform to a uniform annual examination pattern. The variations in the facilities at different medical institutions in Pakistan, the fee structure of the programs, the availability or otherwise of well-run out-patient departments (OPDs) and adequate dedicated faculty for dentistry training appear to be the sources of stress in the local context. ${ }^{8}$ However, there is a dearth of available literature on the prevalence of stress-related outcomes in our dental student population and as yet there are no reliable statistics to understand the gravity of the situation.

Sense of coherence (SOC) is defined as the enduring though dynamic feeling of confidence that a) the stimuli deriving from one's internal and external environments in the course of living are structured, predictable and explicable, b) the resources are available to meet the demands posed by these stimuli and c) these demands are challenges worthy of investment and engagement.". ${ }^{12,13}$ These three components are labelled comprehensibility, manageability and meaningfulness respectively. These traits help individuals in developing coping strategies and deal with the challenging situations in life in a healthy manner. ${ }^{13} \mathrm{SOC}$ has been found to be associated with less anxiety, depressive and burn out findings. ${ }^{12}$ It can be used as a measure of psychological health and well-being. Although SOC continues to develop with time, it has been observed by researchers to be formative and crucial during the second and third decade of life, setting the direction for further progress..$^{12,13}$ This is also the very time that an individual is a university student and hence its applicability in the current context. A lack of coherence can therefore lead to stress, anxiety and burnout in an individual; burnout being the other variable of interest in this study.

Various studies have pointed out an increasing level of stress and mental illness in the Pakistani population. ${ }^{14-17}$ However, there is a dearth of reliable data to indicate the prevalence of stress in students of dentistry. As a bustling metropolis and home to multiple dental teaching institutions in Pakistan, data from Karachi would be crucial to our understanding on the topic.

The study presented here investigated the prevalence of burnout and sense of coherence in students of dentistry in Karachi.

\section{METHODOLOGY}

A cross-sectional, questionnaire based study was carried out involving a total of 361 dentistry students from four renowned dental teaching institutions of Karachi. Data for the total number of registered institutions and dental students in Karachi was obtained from the Pakistan Medical Commission (PMC) website at the following URL:

1. www.pmc.gov.pk/Colleges/PublicDentalColleges

2. www.pmc.gov.pk/Colleges/PrivateDentalColleges The total number of recognized public and private dental colleges in Karachi was found to be 14. The sample size was calculated using Openepi software. At a 95\% confidence level, using simple random sampling, sample size was obtained to be 348. Prior to sampling, the institutions were divided into public and private sector. Then simple random sampling was done using the manual lottery method to select two institutions from each group. Four institutions were sufficient to obtain the required sample size calculated by Openepi software. The actual number of participants in the study were 361 (n). Participation in the study was completely voluntary. The study was conducted from MayDec 2019 after obtaining ethical approval from the ERC of Bahria University Medical and Dental College (Reference no. ERC 20/2020).

The first seven items of the questionnaire were based on the Mayo Clinic Well-Being Index (WBI). The next thirteen questions were based on the modified Antonovsky's 13-item Sense of Coherence Scale (SOC scale). The Mayo 
Clinic Well-being Index is available for IRB-approved studies on request; thereby the WBI Research Document was obtained from MedEd Web Solutions (MEWS) and The Mayo Clinic after submission of an Academic User License Agreement. An individual's score was compared to the normative data from a large national sample of US medical students and professionals. A score of 4 or more was considered to be a sign of distress that warranted seeking help.

Antonovsky's Sense of Coherence Scale (SOC scale) is available in the public domain and describes the individual's ability to adjust with his immediate environment. Various modifications of the scale are available. ${ }^{12,18,19}$ For instance, the revised 13-item sense of coherence scale (SOC-R) has been narrowed down to a 5 point Likert in many countries. ${ }^{19,20}$ In this study, a modified 13 -item version was used with a 4-point Likert Scale (1=always, 2=rarely, $3=$ sometimes, $4=$ never) to quantify the responses to each item. ${ }^{20} \mathrm{~A}$ 4-point Likert has been effectively utilized by other scales like the Brief Coping Scale ${ }^{21}$, General Selfefficacy Scale ${ }^{22}$ and Depression, Anxiety and Stress Scale. ${ }^{23}$ In this study, a 4-point Likert was used by taking advantage of the flexibility of the original scale to allow for cultural modifications and to bring clarity to the students who were finding it confusing to respond to the 7-point version. Crohnbach's alpha reliability coefficient provided a value of 0.721 revealing a high value of internal validity for the scale. A score of 13-52 was calculated with a high score indicating a high sense of coherence. A high sense of coherence is required to deal with stress and related conditions like burnout effectively.

Data was compiled using Microsoft Office (MS Excel) 2010 and analyzed SPSS version 23. Descriptive statistics (frequency, percent values, mean, median, mode, standard deviation) of the variables under study were calculated. The total scores for WBI and SOC scale were considered dependent variables. Age, gender and professional year were considered as independent variables.

Chi-square Test was used to determine any association between the independent and dependent variables. Mann Whitney-U Test and Kruskal Wallis Test was used to compare means between the groups where a positive association was found.

A p-value of equal to or less than 0.05 was considered significant.

\section{RESULTS}

A total of 361 students from four dental institutions of Karachi were surveyed for the study. Data was compiled in SPSS version 23 .
From the total number of respondents, 289(81\%) students were females, 68(19\%) were males (Table 1).

There were $210(58 \%)$ students in the 20-22 years of age bracket, 135(38\%) students were less than 20 years of age and 14 students (4\%) were more than 22 years of age (Table 1).

A total of $170(47 \%)$ respondents were from second year BDS, 68(19\%) were in their third professional, 66(18\%) in the first professional and $57(16 \%)$ in their final professional year. In a cumulative sense, $236(65 \%)$ students were in their pre-clinical years and $125(35 \%)$ in their clinical years (Table 1).

A total of 328(91\%) students were single, 17(5\%) were reported to be in a relationship, $2(0.6 \%)$ were married and $9(2.5 \%)$ had gone through a break-up in their relationship (Table 1).

The majority of respondents, $338(94 \%)$ reported the absence of any chronic medical condition, 346(96\%) reported a lack of any psychiatric condition. The respondents who reported a positive history of chronic medical condition

Table 1: Demographic characteristics and Chi-square Test results

\begin{tabular}{|c|c|c|c|c|}
\hline \multicolumn{4}{|c|}{ Gender } & \multirow[b]{2}{*}{ p-value(SOC) ${ }^{\text {t+ }}$} \\
\hline & Frequency & Valid Percent & p-value(WBI) & \\
\hline Male & 68 & 18.9 & \multirow{2}{*}{$0.023^{*}$} & \multirow{2}{*}{0.511} \\
\hline Female & 289 & 80.5 & & \\
\hline \multicolumn{5}{|c|}{ Age } \\
\hline Less than $20 \mathrm{yrs}$. & 135 & 37.5 & \multirow{3}{*}{0.607} & \multirow{3}{*}{0.702} \\
\hline Between 20-22 yrs. & 210 & 58.3 & & \\
\hline More than 22 yrs. & 14 & 3.9 & & \\
\hline \multicolumn{5}{|c|}{ Professional Year } \\
\hline First Year BDS & 66 & 18.3 & \multirow{4}{*}{$0.001^{*}$} & \multirow{4}{*}{0.057} \\
\hline Second Year BDS & 170 & 47.1 & & \\
\hline Third Year BDS & 68 & 18.8 & & \\
\hline Final Year BDS & 57 & 15.8 & & \\
\hline \multicolumn{5}{|c|}{ Institution } \\
\hline $\mathbf{A}$ & 81 & 22.4 & \multirow{4}{*}{0.063} & \multirow{4}{*}{0.164} \\
\hline B & 52 & 14.4 & & \\
\hline C & 171 & 47.4 & & \\
\hline $\mathbf{D}$ & 57 & 15.8 & & \\
\hline \multicolumn{5}{|c|}{ Relationship Stutus } \\
\hline Single & 328 & 91.1 & \multirow{4}{*}{0.613} & \multirow{4}{*}{0.109} \\
\hline Married & 2 & 0.6 & & \\
\hline In a relationship & 17 & 4.7 & & \\
\hline Broke-up & 9 & 2.5 & & \\
\hline \multicolumn{5}{|c|}{ History of chronic medical condition } \\
\hline Yes & 22 & 6.1 & \multirow{2}{*}{0.649} & \multirow{2}{*}{0.787} \\
\hline No & 338 & 93.9 & & \\
\hline \multicolumn{5}{|c|}{ History of chmonic psychiatric condition } \\
\hline Yes & 13 & 3.6 & \multirow{2}{*}{0.306} & \multirow{2}{*}{0.731} \\
\hline No & 346 & 96.4 & & \\
\hline
\end{tabular}

+ indicates the association of the independent variable with the scores obtained for WBI.

++ indicates the association of independent variable with the scores obtained for SOC Scale.

A p-value $<0.05$ was considered significant; * statistically significant value. 
were $22(6 \%)$ while $13(4 \%)$ reported a history of chronic psychiatric condition (Table 1).

Descriptives for the WBI scores obtained showed a mean value of 4.07 (95\% CI, Std. Dev=2.07) and a median of 4.00 (IQR=3; Table 2). The total students in the "at-risk" category, reporting a score of 4 or more, were found to be 230 (64\%; Fig. 1)

Table 2: Descriptive statistics for the WBI and SOC Scale score.

\begin{tabular}{|ll|c|c|}
\hline & & Statistic & $\begin{array}{l}\text { Std. } \\
\text { Error }\end{array}$ \\
\hline Total Score for WBI & Mean & 4.07 & .109 \\
\cline { 2 - 4 } & Median & 4.00 & \\
\cline { 2 - 5 } & Std. Deviation & 2.077 & \\
& Interquartile Range & 3 & \\
\cline { 2 - 5 } Total Score for SOC & Mewness & -.373 & .128 \\
\cline { 2 - 5 } & Median & 36.39 & .321 \\
\cline { 2 - 5 } & Std. Deviation & 37.00 & \\
\cline { 2 - 5 } & Interquartile Range & 6.101 & \\
\cline { 2 - 5 } & Skewness & 8 & \\
\hline
\end{tabular}

Fig 1: The Mayo Clinic Well-being Index Scores obtained for the total sample $(n=361)$

(A score of 0-3 indicates minimal or no risk for burnout; a score of 4-7 indicates a high risk for burnout)

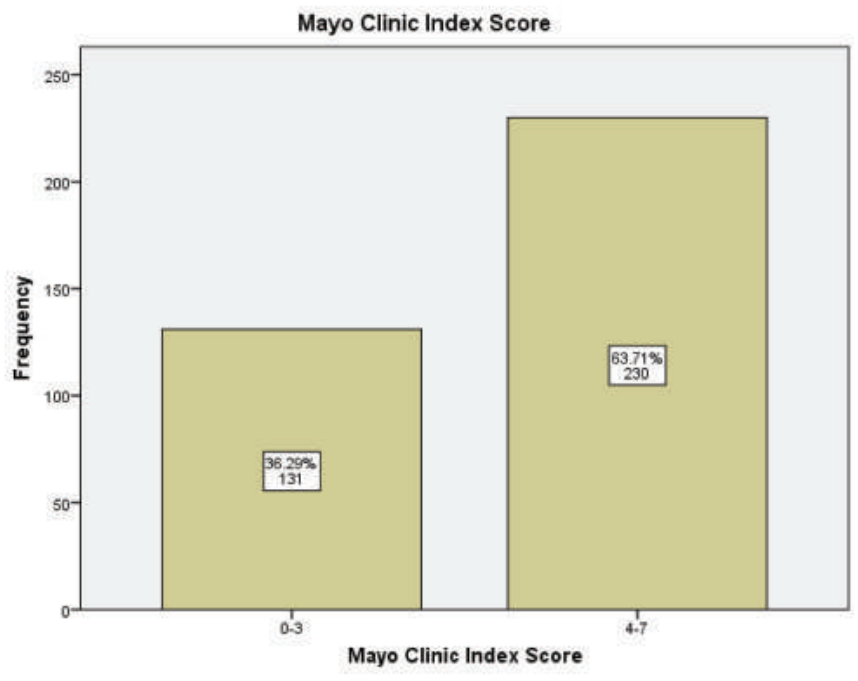

SOC scores produced a mean of 36.39 (95\% CI, Std. $\mathrm{Dev}=6.10)$ and a median of $37.00(\mathrm{IQR}=8$; Table 2). A total of 205(57\%) respondents reported a moderate sense of coherence ranging from 27-39 while $134(37 \%)$ reported a score of 40 or above. A low sense of coherence was reported in 22(6\%) students (Fig. 2).

A significant association was found between gender and WBI scores $(\mathrm{p}=0.023)$. The female students who fell in the "at-risk" category with a score of 4 or more were 192(66\%;
Fig 2: SOC Scale scores obtained for the total sample $(n=361)$

(1 denotes a score of 13-26; 2 denotes a score of 27-39; 3 denotes a score of $40-52$ )

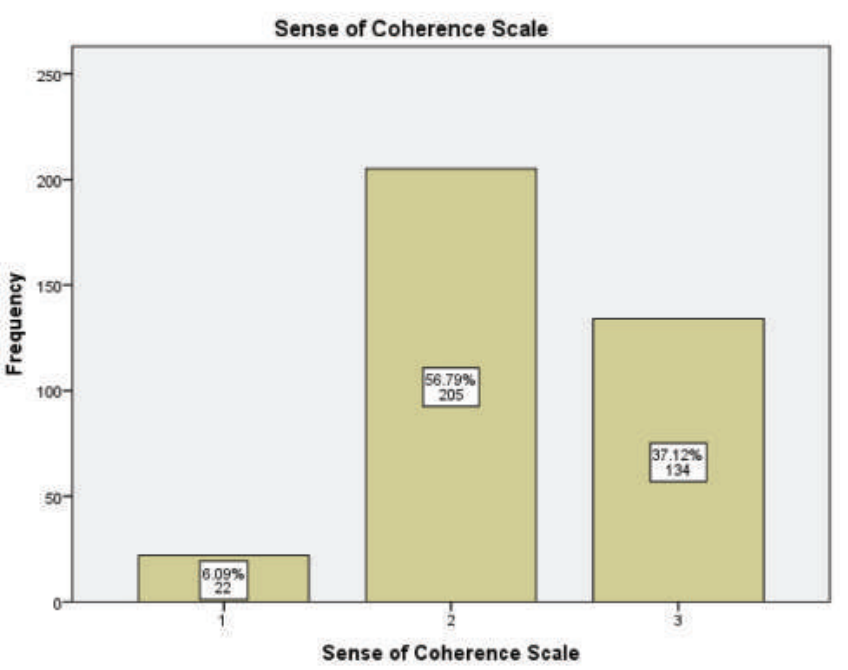

Table 3: Descriptive analysis of WBI and SOC Scale Scores for males and females.

\begin{tabular}{|c|c|c|c|c|c|c|c|c|c|}
\hline & \multicolumn{3}{|c|}{ WBI Score } & \multicolumn{4}{|c|}{ SOC Seore } \\
\hline & & & $\mathbf{1}^{2}$ & $2^{\mathrm{b}}$ & Total & $1^{\varepsilon}$ & $2^{\mathrm{d}}$ & $3^{\circ}$ & Total \\
\hline \multirow{4}{*}{ Gender } & \multirow{2}{*}{$1^{*}$} & Count & 34 & 34 & 68 & 6 & 33 & 29 & 68 \\
\hline & & $\%$ within Gender & $50 \%$ & $50 \%$ & $100 \%$ & $8.8 \%$ & $48.5 \%$ & $42.6 \%$ & $100 \%$ \\
\hline & \multirow{2}{*}{$2 * *$} & Count & 97 & 192 & 289 & 15 & 171 & 103 & 289 \\
\hline & & $\%$ within Gender & $33.6 \%$ & $66,4 \%$ & $100 \%$ & $5.2 \%$ & $59.2 \%$ & $35.6 \%$ & $100 \%$ \\
\hline \multirow{2}{*}{\multicolumn{2}{|c|}{ Total }} & Count & 131 & 228 & 359 & 21 & 205 & 133 & 359 \\
\hline & & $\%$ within Gender & $36.5 \%$ & $63.5 \%$ & $100 \%$ & $5.8 \%$ & $57.1 \%$ & $37 \%$ & $100 \%$ \\
\hline
\end{tabular}

$1^{\mathrm{a}}=$ score $<4 ; 2^{\mathrm{b}}=$ score $>4 ; 1^{\mathrm{c}}=$ score $13-26 ; 2^{\mathrm{d}}=$ score $27-39 ; 3^{\mathrm{e}}=$ score $40-52$.

* male; ** female.

Table 3). For the males, equal numbers (34 students each; $50 \%$ ) were reported in the safe (less than 4) and "at-risk" (4 or more) category (Table 3 ).

For the SOC Scale, no significant association was found between the gender and the scores obtained $(p=0.511)$. A significant association was found between the professional year and the WBI scores obtained $(\mathrm{p}=0.001)$. A total of $52(77 \%)$ third year BDS students, 117(69\%) second year BDS students, 34(52\%) final year students and 28(49\%) first year students were found in the "at-risk" category for the WBI (Table 4).

No significant association was found between year of study and sense of coherence $(\mathrm{p}=0.057)$. However, the highest sense of coherence was found in first year BDS students: $31(47 \%)$. This was reduced successively in second year BDS: $64(38 \%)$ and third year BDS: $15(22 \%)$ while there was a relative increase in final year BDS: 24(42\%). Around $4-9 \%$ of each professional year students exhibited a low sense of coherence (Table 4). 
Table 4: Descriptive analysis of WBI and SOC Scale Scores for males and females.

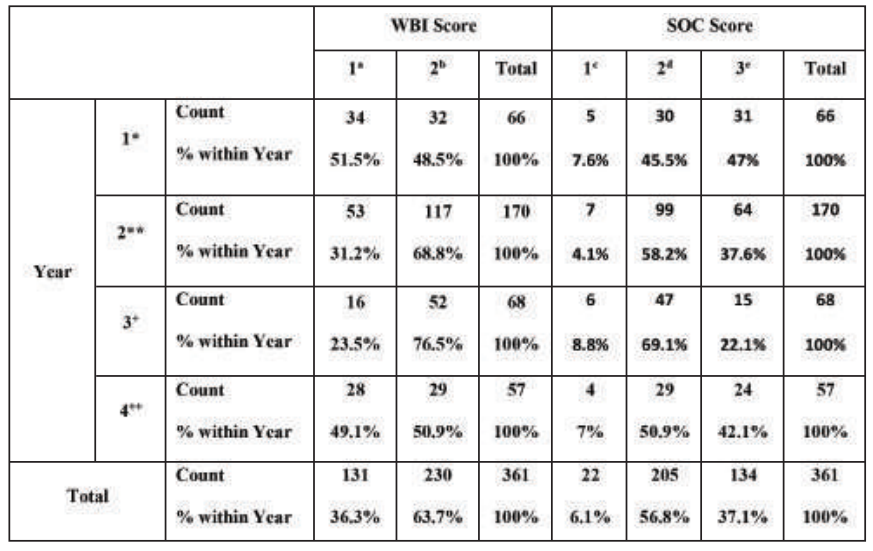

$1^{\mathrm{a}}=$ score $\leq 4 ; 2^{\mathrm{b}}=$ score $\geq 4 ; 1^{\mathrm{c}}=$ score $13-26 ; 2^{\mathrm{d}}=$ score $27-39 ;$ $3^{\mathrm{e}}=$ score $40-52$.

* First year BDS; **Second year BDS; +Third year BDS; ++Final year BDS.

Mann Whitney-U Test revealed a significant difference in the mean scores of males and females for the WBI $(\mathrm{p}=0.041$; Table 5). For SOC, no significant difference in means was found between the genders $(\mathrm{p}=0.294$; Table 5).

Kruskal Wallis Test revealed a significant difference in the mean scores of each professional year for the WBI $(\mathrm{p}=0.012$, Table 6$)$ as well as SOC $(\mathrm{p}=0.045$, Table 6$)$.

Table 5: Comparison of gender-wise score for WBI and SOC Scale using Mann-Whitney Test

\begin{tabular}{|c|c|c|}
\hline & Well-being Index & Sense of Coherence Scale \\
\hline Asymp. Sig. (p-value) & $0.041^{*}$ & 0.294 \\
\hline
\end{tabular}

Grouping Variable: Gender; p-value $\leq 0.05$ denotes significant difference in the scores for each gender.

*Statistically significant value

Table 6: Comparison of professional year-wise score for WBI and SOC Scale using Kruskal-Wallis Test

\begin{tabular}{|l|c|c|}
\hline & Well-being Index & Sense of Coherence Scale \\
\hline Asymp. Sig.(p-value) & $\mathbf{0 . 0 1 2 ^ { * }}$ & $0.045^{*}$ \\
\hline
\end{tabular}

Grouping Variable: Year; p-value $\leq 0.05$ denotes significant difference in the scores for each year.

*Statistically significant value

No significant associations could be established between the other variables and the scores obtained for the WBI. A p-value of $0.607,0.613,0.063,0.649$ and 0.306 was found for age, relationship status, institution and history of chronic medical and psychiatric condition respectively. Similarly, no significant associations were found between these variables and the scores obtained for the SOC. A p-value of $0.702,0.109,0.164,0.787$ and 0.731 was found for age, relationship status, institution and history of chronic medical and psychiatric condition respectively.

\section{DISCUSSION}

As per the data provided by the Mayo Clinic Well-being Index, the overall mean value from their sample of US students was 2.5 and median was $2.0^{24,25}$; the overall mean values obtained for burnout in this study (mean and median=4.0) suggest that the population under study is atrisk of severe outcomes related to stress and burnout. There is a serious need for therapeutic intervention in dental students of Karachi. A systematic review on the subject reveals that atleast $34.1 \%$ of the literature available reports high levels of stress and related conditions in undergraduate dental students and $54.1 \%$ reports moderate levels. ${ }^{26}$ The stress is attributed mainly to the demanding nature of the training. ${ }^{26}$ On the other hand, the SOC values in the current study showed moderate levels of coherence (mean $=36$, median $=37$ ). These may not be sufficient for those students who report a high risk of burnout. ${ }^{3,12}$

The results of the current study also suggest that there is a significant association between year of study and the total scores obtained for the well-being index; third year BDS exhibited the highest risk followed by second year BDS students. There was a relative improvement in the final professional. This can be a logical result as the newly adopted OPD environment in third year can pose a significant challenge for students. ${ }^{27}$ However, the gradual increase in risk from first year to third year needs to be addressed. There may be more than one factor for the increased propensity to stress and burnout. ${ }^{28}$ There is a similar pattern to be observed with the SOC scale. The levels of coherence in this study also drop gradually from first year to third year with a relative improvement observed in the final professional.

M Scholz et al. in a study performed on German pre-clinical dental students ${ }^{3}$ showed similar results with the levels of burnout increasing through each semester upto the end of 2.5 years. The research goes on to state that the students started out at levels comparable with the general population but massive deterioration was observed till the time they were facing their 5 th semester examinations. The same trend was observed when reviewing the same cohort of students using a different set of scales. P.H.M Burger et al. reported that the average levels observed in the fifth semester were equivalent to those of clinical depression. This was in sharp contrast to the levels observed when the students started out their dentistry course in the first semester. ${ }^{3}$ In another study of the dental students of University of Saskatchewan, Western Canada, Alyssa Hayes et $\mathrm{al}^{7}$ reported a higher level of stress among first 
year dental students in many areas, attributed to a fear of failing exams, living away from home, developing manual dexterity etc.

There was also a significant association between gender and the scores obtained for the WBI. A majority of the female students were found to be at risk for developing burn-out while the same could be said about half of the males. What needs to be ascertained is whether this difference actually points to a greater vulnerability of females to stress ${ }^{29,30}$ and/or to some specific work related factors affecting females. ${ }^{31} \mathrm{In}$ another study conducted on Pakistani medical and dental students from Lahore, Najma Naz et al. have also reported that females are more prone to depression, stress and anxiety than males. ${ }^{32}$ Similar results were reported in other ${ }^{7,28,31}$ studies which implicates an association of gender with stress related factors like burnout. However, no significant difference in the levels of coherence between the two genders in this study. This may suggest that a large number of students at risk of burnout need to be facilitated to aid in creating an adequate protective coping mechanism. The fact that more than $80 \%$ of the students in the study were females; which is representative of the current gender imbalance in dentistry students, makes this situation worthy of a quick intervention.

Although some studies have also reported an association between age, relationship status, institution and history of

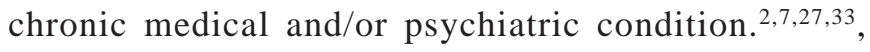
no such associations were found in this study. Karla Gambetta-Tessini et al. in their study of Australian, New Zealand and Chilean dental students showed an interesting finding that those students who opted for dentistry as their first preference for study had decreased stress levels as compared to those students who had wanted to study medicine. ${ }^{33}$

Only a healthy body and mind can deal with the responsibility of thinking logically, producing accurate diagnoses and treating the ailing patients. The importance of a healthy state of mind and well-being for future healthcare professionals dictates that we start paying attention to the creation of a stress-free and conducive environment in our institutions. More research needs to be done to identify the factors implicated in creating stress in our institutions of higher learning. Once we are sure of the significance of each factor, we can gear up to create smart and well-tailored solutions to improve the well-being of our dental students. A major limitation of most studies conducted on the subject including this one was that this was a cross-sectional study. Longitudinal studies following the same cohort of students over the years can provide more accurate information about the students' mental state and the influence of the dental school on them. Also, a baseline measurement of the outcome variables before the start of the academic year for first year students was not available. There was the absence of comparative data from the general population as well. The availability of WBI and SOC Scale scores from a comparable group of Pakistanis or Karachiites would have provided valuable insights into our research. Also, the number of pre-clinical students who responded to the questionnaire was more than that of clinical students.

\section{CONCLUSION AND RECOMMENDATIONS}

Within the limitations of this study, we can conclude that there is a significant number of dental students at risk for burnout and related conditions. There is a need to find ways to raise the levels of coherence in the student community. Further investigation including qualitative research should be carried out to gather data in detail especially regarding the factors contributing to the current scenario. Future studies on this topic may incorporate qualitative assessments, face to face interviews or focus group discussions to yield a more accurate and well-rounded interpretation of findings. Solutions need to be introduced to alleviate the problem at the community as well as institutional level.

\section{ACKNOWLEDGEMENT}

The authors of this study would like to thank MedEd Web Solutions (MEWS) and The Mayo Clinic for providing The Mayo Clinic Well-being Index Research Document after submission of an Academic User License Agreement. Disclaimer: The abstract has neither been previously presented nor published in a conference; nor the manuscript was part of a research, $\mathrm{PhD}$ or thesis project.

\section{CONFLICT OF INTEREST}

There are no financial, personal, or professional interests that could be construed to have influenced the work.

\section{FUNDING DISCLOSURE}

The authors received no financial support for the research, authorship, and/or publication of this article.

\section{REFERENCES}

1. Ishak W, Nikravesh R, Lederer S, Perry R, Ogunyemi D, Bernstein C. Burnout in medical students: a systematic review. The clinical teacher. 2013;10:242-45.

https://doi.org/10.1111/tct.12014

2. Galán F, Ríos-Santos JV, Polo J, Rios-Carrasco B, Bullón P. 
Burnout, depression and suicidal ideation in dental students. Medicina oral, patologia oral y cirugia bucal. 2014;19:e206-11. http://dx.doi.org/doi:10.4317/medoral.19281

3. Scholz M, Neumann C, Ropohl A, Paulsen F, Burger P. Risk factors for mental disorders develop early in German students of dentistry. Annals of Anatom-Anatomischer Anzeiger. 2016;208:204-07. https://doi.org/10.1016/j.aanat.2016.06.004

4. Choy H, Wong M. Occupational stress and burnout among Hong Kong dentists. Hong Kong Med J. 2017;23:480-88. http://doi.org/10.12809/hkmj166143

5. Alhajj M, Khader Y, Murad A, Celebic A, Halboub E, Márquez J, et al. Perceived sources of stress amongst dental students: a multicountry study. Eur J Dent Edu. 2018;22:258-71.

http://doi.org/10.1111/eje.12350

6. Ersan N, Fisekçioglu E, Dölekojlu S, Oktay i, ilgüy D. Perceived sources and levels of stress, general self-efficacy and coping strategies in clinical dental students. Psychology, health \& medicine. 2017;22:1175-85.

https://doi.org/10.1080/13548506.2017.1286359

7. Hayes A, Hoover JN, Karunanayake CP, Uswak GS. Perceived causes of stress among a group of western Canadian dental students. BMC research notes. 2017;10:1-9.

https://doi.org/10.1186/s13104-017-2979-9

8. Jawaid SA. Plight of Dentistry in Pakistan. Pakistan Journal of Medical Sciences. 2020;36:299.

9. Stangvaltaite-Mouhat L, Puriene A, Chalas R, Hysi D, Katrova L, Nacaite M, et al. Self-reported psychological problems amongst undergraduate dental students: A pilot study in seven Eur Countries. Eur J Dent Educ. 2020;00:1-10. http://doi.org/10.1111/eje.12505

10. Kirnbauer B, Ali K. Twenty years after the launch of Bologna Process-What is the status of harmonisation of dental education? Eur J Dent Educ. 2020;24:103-08.

https://doi.org/10.1111/eje.12473

11. Atif S, Qadeer M. Trends of post-graduation in final year dental students and preferences in specific specialty. Pak Oral Dent J. 2019;39:356-59.

12. Carlén K, Suominen S, Lindmark U, Saarinen MM, Aromaa M, Rautava P, et al. Sense of coherence predicts adolescent mental health. J Affective Disorders. 2020;274:1206-10. https://doi.org/10.1016/j.jad.2020.04.023

13. Eriksson M. The sense of coherence in the salutogenic model of health. In: Mittelmark MB, Sagy S, Eriksson M, Bauer GF, Pelikan JM, Lindstrom B, et al. editors The Handbook of Salutogenesis. Cham: Springer (2017), 91-96.

https://doi.org/10.1007/978-3-319-04600-6

14. Gadit A, Vahidy A. Mental health morbidity pattern in Pakistan. J Colle Physic Surg Pakistan. 1999;9:362-65.
15. Khalil R, Naeem Z, Rajar AB, Talib U. A pragmatic perspective on mental disorders by psychiatrists of Karachi, Pakistan: A qualitative study. J Shifa Tameer-e-Millat Uni. 2020;3:34-41. https://doi.org/10.32593/jstmu/Vol3.Iss1.93

16. Asif S, Mudassar A, Shahzad TZ, Raouf M, Pervaiz T. Frequency of depression, anxiety and stress among university students. Pak J Med Sci. 2020;36:971-76.

https://dx.doi.org/10.12669\%2Fpjms.36.5.1873

17. Ahmed B, Enam SF, Iqbal Z, Murtaza G, Bashir S. Depression and anxiety: a snapshot of the situation in Pakistan. International $\mathbf{J}$ Neuroscience Behavioral Sci. 2016;4:32-36. https://doi.org/10.13189/ijnbs.2016.040202

18. Bachem R, Maercker A. Development and psychometric evaluation of a revised sense of coherence scale. Eur J Psychological Assessment. 2016;34:206-15.

https://doi.org/10.1027/1015-5759/a000323

19. Mc Gee SL, Höltge J, Maercker A, Thoma MV. Evaluation of the revised Sense of Coherence scale in a sample of older adults: A means to assess resilience aspects. Aging \& Mental Health. 2018;22:1438-47.

https://doi.org/10.1080/13607863.2017.1364348

20. Lee JW, Jones PS, Mineyama Y, Zhang XE. Cultural differences in responses to a Likert scale. Res Nurs Health. 2002;25:295-306. https://doi.org/10.1002/nur.10041

21. Kocalevent R-D, Zenger M, Hinz A, Klapp B, Brähler E. Resilient coping in the general population: standardization of the brief resilient coping scale (BRCS). Health and quality of life outcomes. 2017;15: $1-8$.

https://doi.org/10.1186/s12955-017-0822-6

22. Zeng G, Fung S-f, Li J, Hussain N, Yu P. Evaluating the psychometric properties and factor structure of the general selfefficacy scale in China. Current Psychology, 2020:1-11. https://doi.org/10.1007/s12144-020-00924-9

23. Stormon N, Ford PJ, Kisely S, Bartle E, Eley DS. Depression, anxiety and stress in a cohort of Australian dentistry students. European J Dent Educ. 2019;23:507-14.

https://doi.org/10.1111/eje.12459

24. Dyrbye LN, Wittlin NM, Hardeman RR, Yeazel M, Herrin J, Dovidio JF, et al. A prognostic index to identify the risk of developing depression symptoms among US medical students derived from a national, four-year longitudinal study. Academ Medi. 2019;94: 217-26.

https://doi.org/10.1097/ACM.0000000000002437

25. Dyrbye LN, Sciolla AF, Dekhtyar M, Rajasekaran S, Allgood JA, Rea M, et al. Medical school strategies to address student wellbeing: a national survey. Academic Medicine. 2019;94:861-68. https://doi.org/10.1097/ACM.0000000000002611

26. Elani HW, Allison PJ, Kumar RA, Mancini L, Lambrou A, Bedos C. A systematic review of stress in dental students. J Dent Educ. 
2014;78:226-42.

https://doi.org/10.1002/j.0022-0337.2014.78.2.tb05673.x

27. Abu-Ghazaleh SB, Sonbol HN, Rajab LD. A longitudinal study of psychological stress among undergraduate dental students at the University of Jordan. BMC medical education. 2016;16:90. https://doi.org/10.1186/s12909-016-0612-6.

28. Radeef AS, Faisal GG. Stressors and Their Association with Symptoms of Depression, Anxiety and Stress in Dental Students. Makara J Healt Res. 2018;22:58-62.

https://doi.org/10.7454/msk.v22i2.9064.

29. Khalid A, Qadir F, Chan SW, Schwannauer M. Adolescents' mental health and well-being in developing countries: a cross-sectional survey from Pakistan. J Ment Healt. 2019;28:389-96. https://doi.org/10.1080/09638237.2018.1521919
30. Karasz A, Gany F, Escobar J, Flores C, Prasad L, Inman A, et al. Mental health and stress among South Asians. J Immig Minority Healt. 2019;21:7-14.

https://doi.org/10.1007/s10903-016-0501-4

31. Malik NAA, Björkqvist K, Österman K. Factors associated with occupational stress among university teachers in Pakistan and Finland. J Educ, Health Commu Psycholog. 2017;6:1-14.

32. Naz N, Iqbal S, Mahmood A. Stress, anxiety and depression among the dental students of university college of medicine and dentistry Lahore; Pakistan. Pak J Med Health Sci. 2017;11:1277-281.

33. Gambetta-Tessini K, Mariño R, Morgan M, Evans W, Anderson V. Stress and health-promoting attributes in Australian, New Zealand, and Chilean dental students. J Dent Educ. 2013;77:801-9. https://doi.org/10.1002/j.0022-0337.2013.77.6.tb05532.x 